\title{
Clinical Profile of the Patients with Newly Detected Left Bundle Branch Block in the Outpatient Department
}

\author{
Bino Benjamin \\ Department of Cardiology, Kottayam Medical College, Kottayam, India \\ Email: binobenjaminc@gmail.com
}

How to cite this paper: Benjamin, B. (2018) Clinical Profile of the Patients with Newly Detected Left Bundle Branch Block in the Outpatient Department. World Journal of Cardiovascular Diseases, 8, 143-151. https://doi.org/10.4236/wjcd.2018.82014

Received: December 21, 2017

Accepted: February 9, 2018

Published: February 12, 2018

Copyright $\odot 2018$ by author and Scientific Research Publishing Inc. This work is licensed under the Creative Commons Attribution International License (CC BY 4.0).

http://creativecommons.org/licenses/by/4.0/

\begin{abstract}
Objective: The purpose of this study was to evaluate cardiac features associated with newly detected left bundle branch block (LBBB) in the outpatient department. Methods: A total of 57 patients with LBBB pattern were evaluated using electrocardiography (ECG). Patients were assessed based on their sex, age, detailed history, and cardiovascular symptoms. Cardiac investigations including ECG and echocardiography were performed. Results: The study included $30(52.6 \%)$ males and $27(47.5 \%)$ females, aged between 35 and 80 years. Dyspnoea $(35.1 \%)$ and chest pain $(22.8 \%)$ were the most common symptoms. $54.4 \%$ were hypertensive and $17.5 \%$ were diabetics. $28 \%$ had Left ventricular systolic dysfunction, and $24.5 \%$ had aortic valve disease. Left ventricular hypertrophy without any other structural heart disease was present in $28 \%$ of the patients. Only $24.5 \%$ patients presented with LBBB had a structurally normal heart in echocardiography. Myocardial performance index in echocardiography was abnormal in LBBB irrespective of the presence of structural heart disease. Conclusion: The prevalence of LBBB was found to increase with age and had slight male preponderance. Dyspnoea on effort was the most common presenting complaint, followed by chest pain and incidental detection of ECG abnormality. Most of the patients were hypertensive. Only $24.5 \%$ patients with LBBB had a structurally normal heart. MPI was abnormally high in the presence of LBBB despite having a normal left ventricular ejection fraction.
\end{abstract}

\section{Keywords}

Left Bundle Branch Block, Echocardiography, Electrocardiography

\section{Introduction}

Left bundle branch block (LBBB) is an electrical cardiac conduction abnormality 
in the main left bundle branch. In this condition, the left ventricle activation is delayed, which delays the contraction of left ventricle later than the right ventricle [1] [2]. LBBB is also defined as the duration of the QRS on the electrocardiography (ECG) greater than $120 \mathrm{~ms}$, slurred R wave in leads I, V5, and V6, RS pattern in V5 and V6, and absent Q waves in left lateral leads [3]. Framingham studies have shown that changes in QRS voltage and ventricular repolarization are a significant factor in determining cardiovascular diseases [4]. LBBB is commonly seen in patients with underlying heart disease [5]. LBBB is also a known risk factor for cardiovascular morbidity and mortality in the general population [6]. The lifetime risk development of LBBB is $0.7 \%$ in healthy male subjects [3]. LBBB is also a strong adverse prognostic sign associated with sudden cardiac mortality in patients [7]. LBBB alters the pattern of ECG which is associated with left ventricular hypertrophy (LVH) [8]. It is related to cardiovascular pathologies involving the conduction system and the myocardium, such as coronary artery disease (CAD), cardiomyopathy, LVH, and drug effects [9] [10]. Moreover, LBBB can be observed in the absence of any of these risk factors with structurally normal heart in some patients [3]. LBBB is most commonly correlated with CAD. Among patients with CAD, the presence of LBBB correlates with more extensive disease. Sometimes it is the only manifestation of acute myocardial infarction [11]. LBBB with left axis deviation has a worse diagnosis than LBBB with a normal axis, and common causes of left axis deviation include myocardial dysfunction [12]. Some studies have revealed a correlation between LBBB and left ventricle systolic and diastolic dysfunction in patients [13]. The myocardial performance index (MPI) is quantifiable with tissue Doppler echocardiography index. However, MPI provides the information about combined systolic and diastolic functions and is reported to be investigated from the point of analysis of its relation to heart diseases. MPI has been demonstrated to determine parameters in both the diagnostic and prognostic of different cardiac events [14]. The prevalence of LBBB in patients attending cardiology outpatients and various etiologies of LBBB has not been studied previously. Therefore, the present study was to investigate cardiac features associated with newly detected LBBB in the outpatient department. Also, we assessed whether MPI could be used to predict left ventricular function outcome in patients with LBBB.

\section{Methods}

The study was undertaken at Kottayam medical college, in the department of cardiology from September 2005 to August 2006. Fifty-seven patients with LBBB pattern in the ECG were included in this study. Patients were having a documented LBBB and on follow-up in the cardiology, or medical outpatient department were excluded from this study. Also, patients with features and symptoms suggestive of the acute coronary syndrome were excluded. Prior to the initiation of the study, the protocol was approved by institutional ethical committee (IEC). 


\subsection{Patient Population and Study Design}

Detailed history, clinical parameters and cardiovascular symptoms were assessed. ECG and echocardiography were also performed. During echocardiography, all routine chamber measurements, left ventricular ejection fraction (LVEF), Doppler evaluation of the flow across each valve and MPI were assessed. MPI as a simple and consistent index of a sum of isovolumic contraction time (IVCT) and isovolumic relaxation time (IVRT) divided by ejection time (ET) was calculated by Tei et al. [15] as shown in Figure 1. The sum of IVCT and IVRT is equal to the difference between the interval from Cessation to the onset of the Mitral inflow (MCO) and ET.

$$
\text { MPI }=(\text { IVCT }+ \text { IVRT }) / \text { ET }
$$

where, IVRT $=$ measured from a closure of aortic valve and opening of mitral valve, IVCT = measured from a closure of mitral valve and opening of aortic valve, $\mathrm{ET}=$ measured from opening and the closure of the aortic valve on the left ventricular outflow velocity profile.

\subsection{Statistical Analysis}

Statistical analysis was carried out using Microsoft Excel spreadsheet (version 2007, Microsoft Corp, Seattle, Washington). Values were expressed as a mean \pm standard deviation or as percentages.

\section{Results}

The age of the patients varied between 35 - 80 years. The mean age was 62.7 years. Among 57 patients, 30 (52.6\%) were males, and 27 (47.3\%) were females in the studied population. Table 1 shows the baseline characteristics of $57 \mathrm{pa}-$ tients. The most common clinical presentation was dyspnoea, in 20 (35.1\%)

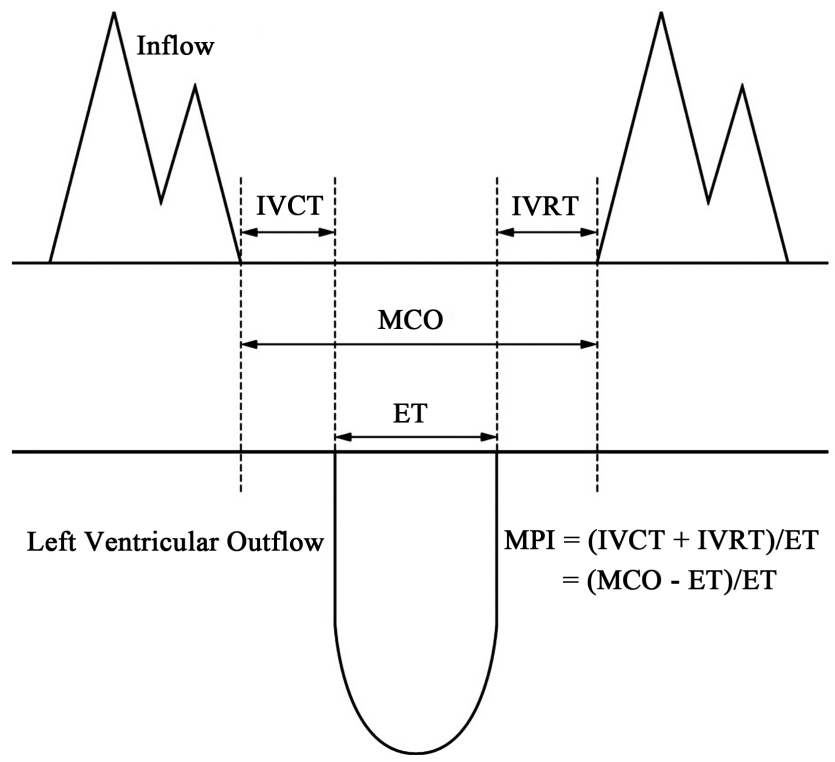

Figure 1. Doppler evaluation of myocardial performance index (MPI). 
Table 1. Baseline characteristics of the study population $(n=57)$.

\begin{tabular}{|c|c|}
\hline Characteristics & $(\mathrm{n}=57)$ \\
\hline Age & 62.7 \\
\hline \multicolumn{2}{|l|}{ Gender } \\
\hline Male & $30(52.6 \%)$ \\
\hline Female & $27(47.3 \%)$ \\
\hline \multicolumn{2}{|l|}{ Symptoms } \\
\hline Dyspnoea & $20(35.1 \%)$ \\
\hline Incidental & $17(29.8 \%)$ \\
\hline Chest pain & $13(22.8 \%)$ \\
\hline Angina & $4(7 \%)$ \\
\hline Others & $11(19.3 \%)$ \\
\hline \multicolumn{2}{|l|}{ Clinical Examination } \\
\hline Hypertension & $31(54.4 \%)$ \\
\hline Diabetes mellitus & $10(17.5 \%)$ \\
\hline Smoking & $10(17.5 \%)$ \\
\hline COPD & $6(10.5 \%)$ \\
\hline CAD & $9(15.8 \%)$ \\
\hline Anterior wall MI & $5(8.8 \%)$ \\
\hline Effort Angina & $1(1.8 \%)$ \\
\hline Unstable angina & $1(1.8 \%)$ \\
\hline Unknown & $2(3.5 \%)$ \\
\hline Syncope & $2(3.5 \%)$ \\
\hline Fever & $1(1.8 \%)$ \\
\hline Sinus rhythm & $55(96.5 \%)$ \\
\hline Atrial Fibrillation & $2(3.5 \%)$ \\
\hline $\mathrm{LVS}_{3}$ & $5(8.8 \%)$ \\
\hline $\mathrm{LVS}_{4}$ & $11(19.3 \%)$ \\
\hline Basal ESM & $12(21 \%)$ \\
\hline Apical Systolic Murmur & $7(12.3 \%)$ \\
\hline \multicolumn{2}{|l|}{ Non-Cardiac Symptoms } \\
\hline Leptospiral myocarditis & $1(1.8 \%)$ \\
\hline Stroke & $1(1.8 \%)$ \\
\hline Hyperthyroidism & $1(1.8 \%)$ \\
\hline Hypothyroidism & $1(1.8 \%)$ \\
\hline PVOD & $1(1.8 \%)$ \\
\hline ACA aneurysm & $1(1.8 \%)$ \\
\hline Pneumonia & $1(1.8 \%)$ \\
\hline Cirrhosis & $1(1.8 \%)$ \\
\hline
\end{tabular}

COPD—Chronic obstructive pulmonary disease, CAD—Coronary artery disease, MI-Myocardial infarction, LVS3 and LVS4-Left ventricle S3 and S4, ESM-Ejection systolic murmur, PVOD—Pulmonary veno-occlusive disease, ACA-anterior cerebral artery. 
patients, chest pain in $13(22.8 \%)$ patients, typical angina in $4(7 \%)$ patients, syncope in 2 (3.5\%) patients and fever in 1 (1.8\%). Seventeen (29.8\%) LBBB was detected incidentally during evaluation of non-cardiac symptoms. In our study, around $31(54.4 \%)$ patients were hypertensives, 10 (17.5\%) patients were diabetics, $10(17.5 \%)$ patients were smokers and $6(10.5 \%)$ had chronic obstructive pulmonary disease (COPD). Among 9 (15.8\%) CAD patients, five patients had anterior wall myocardial infarction, $1(1.8 \%)$ patient had a history of unstable angina, $1(1.8 \%)$ patient was on treatment for chronic stable angina and in 2 (3.5\%) patients, the nature of CAD was not clear. 55 (96.5\%) patients were in sinus rhythm, and 2 (3.5\%) patients had atrial fibrillation. Left ventricle S3 and left ventricle 44 were present in $8.8 \%$ and $19.3 \%$ patients respectively. As shown in Table 2, mean PR interval was $156.36 \mathrm{~ms}$ (120 - $260 \mathrm{~ms})$, and two patients

Table 2. ECG and Echocardiography data of study group.

\begin{tabular}{|c|c|c|}
\hline \multicolumn{3}{|c|}{$(\mathrm{n}=57)$} \\
\hline ECG & & \\
\hline PR interval (ms) & $156.36(120-260)$ & \\
\hline Mean QRS axis (ms) & $-17.10\left(-60^{\circ}\right.$ to $\left.+60^{\circ}\right)$ & \\
\hline Mean QRS width (ms) & $133.33(120-160)$ & \\
\hline Mean QTc (ms) & $433.59(400-500)$ & \\
\hline LAE-ECG & $9(15.8 \%)$ & \\
\hline Echocardiography & LBBB & Normal \\
\hline LVIDd (cm) & $4.74(3.3-6.7)$ & $4.47(4.60)$ \\
\hline LVIDs (cm) & $3.49(2.16-5.97)$ & $2.92(3.35)$ \\
\hline LVEF (\%) & $59.78(18 \%-82 \%)$ & $67(61.75 \%)$ \\
\hline LA size & $3.75(2.7-5.7)$ & $3.67(3.66)$ \\
\hline Mean MPI & $0.67(0.3-1.47)$ & $0.66(0.70)$ \\
\hline Conc LVH & $32(56.14 \%)$ & \\
\hline Mean TR & $28.58(14-63)$ & \\
\hline RWMA & $6(10.5 \%)$ & \\
\hline Mitral Regurgitation & $18(31.6 \%)$ & \\
\hline Aortic Regurgitation & $13(22.8 \%)$ & \\
\hline Aortic Stenosis & $4(7 \%)$ & \\
\hline Sclerotic Aortic valve & $14(24.6 \%)$ & \\
\hline Aortic valve disease & $14(24.5 \%)$ & \\
\hline LVD & $16(28.0 \%)$ & \\
\hline Only LVH & $16(28.0 \%)$ & \\
\hline Structural normal heart & $14(24.5 \%)$ & \\
\hline
\end{tabular}

LAE - left atrial dilatation, ECG- Electrocardiography, LVIDd - Left ventricular internal diameter end diastole, LVIDs-Left ventricular internal diameter end systole, LVEF-left ventricular ejection fraction, LA size-Left atrial size, MPI-Myocardial performance index, Conc LVH-left ventricular hypertrophy, TR-Tricuspid regurgitation, RWMA-Regional wall motion abnormality, LVD—Left ventricular dysfunction. 
with LBBB had prolonged PR interval. Mean QRS axis duration and QRS width were $-17.10\left(-60^{\circ}\right.$ to $\left.+60^{\circ}\right)$ and $133.33 \mathrm{~ms}(120-160 \mathrm{~ms})$, respectively. The mean QTc interval was $433.6 \mathrm{~ms}$ (400 - $500 \mathrm{~ms}$ ). Furthermore, 9 (15.8\%) patients had left atrial dilatation in ECG. The echocardiographic data of study groups are presented in Table 2. The mean left ventricular internal diameter end diastole, and end systole was $4.74 \mathrm{~cm}(3.3-6.7 \mathrm{~cm})$ and $3.49 \mathrm{~cm}(2.16-5.97 \mathrm{~cm})$, respectively. Mean LVEF was $59.78 \%(18 \%-82 \%)$. Mean left atrial dimension was $3.75 \mathrm{~cm}(2.7$ to $5.7 \mathrm{~cm})$. Concentric LVH was present in $32(56.14 \%)$ patients. Regional wall motion abnormality suggestive of coronary artery disease was present only in $6(10.5 \%)$ in a left anterior descending region in the patients. Mild mitral regurgitation was seen in $18(31.6 \%)$ patients and moderate mitral regurgitation in $4(7.0 \%)$ patients. $14(24.6 \%)$ patients had a sclerotic aortic valve. Among those, 13 (22.8\%) patients had aortic regurgitation, (2 (3.5\%) patients had moderate, and $11(19.2 \%)$ had mild aortic regurgitation). Aortic stenosis was present in 4 patients (7\%), out of which 2 (3.5\%) patients had severe aortic stenosis. Furthermore, 16 (28\%) patients had left ventricle systolic dysfunction. After excluding those patients with aortic valve sclerosis, 14 patients (24.5\%) had aortic valve disease, and LVH was present in 16 (28\%) patients. 14 (24.5\%) patients had a structurally normal heart. Mean myocardial performance index (MPI) was $0.67(0.30-1.47)$. The structurally normal heart patients were analyzed as shown in Table 2. In patients with normal heart, MPI was 0.66. MPI was 0.70 in the total group. This value of MPI was high for a normal heart without LBBB, where a value above 0.50 is taken as abnormal.

\section{Discussion}

The present study elucidated whether the MPI can be used to predict left ventricular function with the presence of newly detected LBBB in ECG. LBBB is also associated with functional impairment of hemodynamic, systolic and diastolic function. It is accompanied by progressive left ventricle dilatation and mitral regurgitation [16]. The Framingham study revealed a clear association between LBBB and severe cardiovascular diseases such as hypertension, coronary heart disease and cardiac enlargement [17]. Our study result demonstrated that about $54.4 \%$ patients with LBBB had hypertension; around $15.8 \%$ patients had CAD, and left ventricle systolic dysfunction was present in $28 \%$ patients. In similar studies by Bhardwaj et al., $48 \%$ patients with LBBB had hypertension, $23 \%$ patients had CAD, and left ventricle systolic dysfunction was present in about $56 \%$ patients. The majority of their patients were aged 50 years or more [18]. These findings were similar to our study, the majority of patients were above 50 years or older with slight male preponderance. Among 57 patients, dyspnoea (35.1\%) on effort was the most common symptom, followed by chest pain and incidental detection of ECG abnormality. Our study results were nearly consistent with Bharath et al. which reported common presentation was dyspnoea (35.3\%) followed by chest pain in patients with LBBB. In this study, PR interval, QRS axis, 
and QRS width were also assessed in patients with LBBB. In the presence of LBBB, most of the patients had a PR interval, QRS axis, and QRS width within the normal range. Among eight patients who had left axis deviation (i.e., axis beyond -60 to the left), only 2 had a structurally normal heart. Park et al. study which reported that $\mathrm{LBBB}$ with left axis deviation has an inferior prediction than LBBB with a normal axis. The myocardial disease has been suggested as a significant cause of left axis deviation [12]. We found that the left axis deviation in ECG is more common among patients with structural heart disease. In the current study, the echocardiographic manifestation left ventricle systolic dysfunction was present in about $28 \%$ patients. Our study results of left ventricle systolic dysfunction agreed with Bharath et al. [3]. After excluding patients with aortic valve sclerosis without significant left ventricular outflow tract obstruction, $24.5 \%$ patients had aortic valve disease. LVH without any other structural heart disease was present in $28 \%$ patients. The structurally normal heart was presented only in $24.5 \%$ patients with LBBB. This result was similar to the study by Bharath et al. and Bhargava et al. [3] [19]. Furthermore, left atrial size was almost same between LBBB and normal heart patients. Most of the echocardiography parameters were different between LBBB and normal heart patients based on MPI findings. The values of MPI were above that of the normal heart without LBBB. The MPI in echocardiography was abnormal in LBBB irrespective of the presence of structural heart disease. The study shows that MPI did not have much value in the assessment of Left ventricular function in the presence of LBBB in ECG.

\section{Study Limitations}

The present study had a few possible limitations. The number of patients with LBBB was relatively less, and the follow-up period was short. Patients with characteristic and sign suggestive of the acute coronary syndrome were excluded from this study.

\section{Conclusion}

The prevalence of LBBB was found to increase with age and had slight male preponderance. Dyspnoea on effort was the most common presenting complaint, followed by chest pain and incidental detection of ECG abnormality. Most of the patients were hypertensives. Only $24.5 \%$ patients with LBBB had a structurally normal heart. MPI was abnormally high in the presence of LBBB despite having a normal LVEF.

\section{Conflicts of Interest}

The authors declare no conflicts of interest.

\section{References}

[1] Auricchio, A., Fantoni, C., Regoli, F., Carbucicchio, C., Goette, A., Geller, C., Kloss, 
M. and Klein, H. (2004) Characterization of Left Ventricular Activation in Patients with Heart Failure and Left Bundle-Branch Block. Circulation, 109, 1133-1139. https://doi.org/10.1161/01.CIR.0000118502.91105.F6

[2] Lépori, A.J., Mishima, R.S., Rodriguez, G., Moreyra, E.A., Serra, J.L., Tibaldi, M.A., Martellotto, A. and Moreyra Jr., E. (2015) Relationship between Electrocardiographic Characteristics of Left Bundle Branch Block and Echocardiographic Findings. Cardiology Journal, 22, 397-403. https://doi.org/10.5603/CJ.a2015.0005

[3] Bharath, M., Sunayana, N. and Channakeshava, S. (2017) Diagnostic and Prognostic Value of Left Bundle Branch Block and Its Correlation with Left Ventricular Functions: A Prospective Observational Study. International Journal of Advances in Medicine, 4, 713-717. https://doi.org/10.18203/2349-3933.ijam20172100

[4] Prineas, R.J., Rautaharju, P.M., Grandits, G., Crow, R. and Group, M.R. (2001) Independent Risk for Cardiovascular Disease Predicted by Modified Continuous Score Electrocardiographic Criteria for 6-Year Incidence and Regression of Left Ventricular Hypertrophy among Clinically Disease Free Men: 16-Year Follow-Up for the Multiple Risk Factor Intervention Trial. Journal of Electrocardiology, 34, 91-101. https://doi.org/10.1054/jelc.2001.23360

[5] Alhaji, M. (2013) Intermittent Left Bundle Branch Block Caused by Coronary Vasospasm. Avicenna Journal of Medicine, 3, 50-52.

https://doi.org/10.4103/2231-0770.114129

[6] Eriksson, P., Wilhelmsen, L. and Rosengren, A. (2005) Bundle-Branch Block in Middle-Aged Men: Risk of Complications and Death over 28 Years. The Primary Prevention Study in Goteborg, Sweden. European Heart Journal, 26, 2300-2306. https://doi.org/10.1093/eurheartj/ehi580

[7] Baldasseroni, S., Opasich, C., Gorini, M., Lucci, D., Marchionni, N., Marini, M., Campana, C., Perini, G., Deorsola, A., Masotti, G., Tavazzi, L. and Maggioni, A.P. (2002) Left Bundle-Branch Block Is Associated with Increased 1-Year Sudden and Total Mortality Rate in 5517 Outpatients with Congestive Heart Failure: A Report from the Italian Network on Congestive Heart Failure. American Heart Journal, 143, 398-405. https://doi.org/10.1067/mhj.2002.121264

[8] Sundström, J., Lind, L., Andren, B. and Lithell, H. (1998) Left Ventricular Geometry and Function Are Related to Electrocardiographic Characteristics and Diagnoses. Clinical Physiology and Functional Imaging, 18, 463-470. https://doi.org/10.1046/j.1365-2281.1998.00126.x

[9] Surawicz, B., Childers, R., Deal, B.J., Gettes, L.S., Bailey, J.J., Gorgels, A., Hancock, E.W., Josephson, M., Kligfield, P., Kors, J.A., Macfarlane, P., Mason, J.W., Mirvis, D.M., Okin, P., Pahlm, O., Rautaharju, P.M., van Herpen, G., Wagner, G.S. and Wellens, H. (2009) AHA/ACCF/HRS Recommendations for the Standardization and Interpretation of the Electrocardiogram: Part III: Intraventricular Conduction Disturbances: A Scientific Statement from the American Heart Association Electrocardiography and Arrhythmias Committee, Council on Clinical Cardiology; the American College of Cardiology Foundation; and the Heart Rhythm Society: Endorsed by the International Society for Computerized Electrocardiology. Circulation, 119, e235-e240. https://doi.org/10.1161/CIRCULATIONAHA.108.191095

[10] Deniz, A., Ozmen, C., Aktas, H., Berk, I.G., Deveci, O.S., Cagliyan, C.E., Eker Akilli, R., Kanadasi, M., Demir, M. and Usal, A. (2016) Electrocardiographic Markers of Left Ventricular Systolic Dysfunction in Patients with Left Bundle Branch Block. Kardiologia polska, 74, 25-31. https://doi.org/10.5603/KP.a2015.0119

[11] Freedman, R.A., Alderman, E.L., Thomas Sheffield, L., Saporito, M. and Fisher, L.D. (1987) Bundle Branch Block in Patients with Chronic Coronary Artery Disease: 
Angiographic Correlates and Prognostic Significance. Journal of the American College of Cardiology, 10, 73-80. ttps://doi.org/10.1016/S0735-1097(87)80162-6

[12] Park, C.S., Cha, M.-J., Choi, E.-K. and Oh, S. (2017) Prognostic Implication of the QRS Axis and Its Association with Myocardial Scarring in Patients with Left Bundle Branch Block. Korean Circulation Journal, 47, 263-269. https://doi.org/10.4070/kcj.2016.0359

[13] Özdemir, K., Altunkeser, B.B., Daniş, G., Özdemir, A., Uluca, Y., Tokaç, M., Telli, H.H. and Gök, H. (2001) Effect of the Isolated Left Bundle Branch Block on Systolic and Diastolic Functions of Left Ventricle. Journal of the American Society of Echocardiography, 14, 1075-1079. https://doi.org/10.1067/mje.2001.115655

[14] Akif Duzenli, M., Ozdemir, K., Soylu, A., Aygul, N., Yazici, M. and Tokac, M. (2008) The Effect of Isolated Left Bundle Branch Block on the Myocardial Velocities and Myocardial Performance Index. Echocardiography, 25, 256-263. https://doi.org/10.1111/j.1540-8175.2007.00579.x

[15] Tei, C., Ling, L.H., Hodge, D.O., Bailey, K.R., Oh, J.K., Rodeheffer, R.J., Tajik, A.J. and Seward, J.B. (1995) New Index of Combined Systolic and Diastolic Myocardial Performance: A Simple and Reproducible Measure of Cardiac Function-A Study in Normals and Dilated Cardiomyopathy. Journal of cardiology, 26, 357-366.

[16] Littmann, L. and Symanski, J.D. (2000) Hemodynamic Implications of Left Bundle Branch Block. Journal of Electrocardiology, 33, 115-121. https://doi.org/10.1054/jelc.2000.20330

[17] Schneider, J.F., Thomas, H.E., Jr., Kreger, B.E., McNamara, P.M. and Kannel, W.B. (1979) Newly Acquired Left Bundle-Branch Block: The Framingham Study. Annals of Internal Medicine, 90, 303-310. https://doi.org/10.7326/0003-4819-90-3-303

[18] Bhardwaj, R. (2016) Etiology and Left Ventricular Functions in Left Bundle Branch Block-A Prospective Observational Study. The Journal of the Association of Physicians of India, 64, 36-38.

[19] Bhargava, M., Sethi, K.K., Murthy, G.S., Gambhir, D.S., Kalra, G.S., Mohan, J.C., Arora, R. and Khalilullah, M. (1994) Ventricular Tachycardia with Left Bundle Branch Block Morphology in the Absence of Ischaemic Heart Disease-Clinical and Electrophysiological Observations. Indian Heart Journal, 46, 287-290. 